\section{Neuroradiology Fellowship Requirements: Updates in 2019}

\author{
(D) T.A. Kennedy and (D). Anderson
}

T he revised Accreditation Council for Graduate Medical Education (ACGME)-accredited Neuroradiology Fellowship Requirements were recently implemented in July 2019. The revision process was facilitated by a task force that was coordinated by the American Society of Neuroradiology (ASNR). The most notable changes made since the prior requirements were last revised in 2007 primarily affect the number of required procedures, the academic support defined for the program director, and modifications to the curriculum. The new requirements allow fellows to fulfill the foundational expectations for the neuroradiology fellowship and encourage programs to maintain some flexibility to teach individual specialty areas of clinical excellence.

The ACGME is a national organization that establishes accreditation guidelines for many graduate medical programs in the United States, including the Neuroradiology Fellowship Program, which is sponsored by the ASNR. The ACGME periodically and systematically reviews these requirements for each specialty program, making revisions every 10-12 years based on input of the sponsoring specialty society, which are intended to incorporate current and anticipated changes in medical practice.

The Neuroradiology Fellowship Requirements were initially established in 1990 and were last fully revised in 2007. ${ }^{1}$ The updated Neuroradiology Fellowship Requirements, which incorporated the recently approved Common Program Requirements (CPRs), were approved by the ACGME in February 2019 and went into effect July 1, 2019. ${ }^{2}$ In this Editorial, the Neuroradiology Fellowship Requirements revision process is discussed as well as the key changes from the prior requirements.

\section{The ASNR Committee Process}

An ACGME Requirement Revision Task Force was created with direction from the ASNR Fellowship Directors Committee to generate a list of recommendations to be submitted on behalf of the ASNR to the ACGME Radiology Review Committee to address any programmatic and curricular changes in the ACGME Neuroradiology Fellowship Requirements. The task force consisted of Fellowship Directors, ASNR Executive Committee members, and Young Professional Section members, with a concerted effort to create a group that represented a diversity of programs of different sizes, geography, and specialty areas of excellence across the country. In addition, feedback and input were solicited from subspecialty society leadership from the American Society of Head and Neck Radiology, American Society of Spine Radiology, American Society of Functional Neuroradiology, American Society of Pediatric Neuroradiology, and the Society of Neurointerventional Surgery.

http://dx.doi.org/10.3174/ajnr.A6450
The major revision update happened to coincide with the ACGME review and update of the underlying Common Program Requirements (CPR). These CPRs are the elements of the program requirements that are common to all specialties or, in this case, to the subspecialties. These also provide the framework for any specialty or subspecialty requirements. Thus, elements in the 2019 updated Neuroradiology Fellowship Requirements also include items that were not a result of the process described above but rather due to inclusion by the recommendation of the ACGME CPR revision task force.

\section{Key Changes in the 2019 Updated Requirements}

The revision task force began its process on the basis of the understanding that there are fundamental core standards that all ACGME-accredited Neuroradiology Fellowship programs should meet so that any fellow graduating from an accredited program should possess a core set of uniform skills necessary to practice neuroradiology. There is also acknowledgment that neuroradiology programs may individually have certain content areas of expertise. The new requirements allow programs some flexibility to meet core standards but, in so doing, provide an opportunity for programs to have flexibility to offer unique experiences to their trainees.

A number of modifications to the Neuroradiology Fellowship Requirements have been made to reflect contemporary clinical practice guidelines that are different from what they were in 2007. The new requirements address shifting expectations related to neuroangiography, redefine the fellowship curriculum, and outline support for fellowship program directors.

Program Director. To acknowledge the substantial time commitment of the Fellowship Program Director (PD) to administer the neuroradiology training program, changes have been made to provide protected academic time to the Fellowship PD based on a sliding scale. As part of the new requirements, the PD should have protected administrative time and should be granted a minimum of 0.1 full-time equivalent (FTE) for a program with 1-5 fellows and 0.2 FTE for a program with more than 5 fellows (II.A.2.a). ${ }^{2}$ Note that these requirements are based on the approved complement and not on the actual number of fellows enrolled, a subtle-but-important distinction to understand. This protected administrative time was not specified in the prior version. A similar requirement has been incorporated in the core Diagnostic Radiology Residency Requirements as well as within the Interventional Radiology Residency Requirements. In addition, as a prerequisite, PDs should have 3 years of clinical experience and be subspecialty certified (II.A.3). ${ }^{2}$ A summary of the Program Director, Program Coordinator, and Program Faculty requirements is listed in Table 1.

Patient Care and Procedural Skills. Meaningful changes were made to the Patient Care and Procedural Skills section of the requirements. Fellows are now required to interpret a minimum of 3000 total examinations, of which, at least 1500 should be MR imaging studies (IV.B.1.b).(2).(a).(i). ${ }^{2}$ Previously, fellows were 
Table 1: Program director, coordinator, and participating faculty requirements

\begin{tabular}{ll}
\hline \multicolumn{1}{c}{ Program Role } & \multicolumn{1}{c}{ Requirements (Minimum) } \\
\hline Program director academic time & 1-5 Fellows approved - 0.1 FTE (10\%) \\
& $>6$ Fellows approved - 0.2 FTE (20\%) \\
Program director experience & 3 Years of clinical experience \\
& Subspecialty certification by the American Board of Radiology \\
Program coordinator & The program coordinator must be provided with adequate time and support, depending \\
& on the size of the program \\
Participating faculty & Minimum of 2 neuroradiology faculty (including the PD) \\
& Faculty should spend 80\% of time practicing neuroradiology \\
& Ratio of at least 1 neuroradiologist for every 2 fellows \\
\hline
\end{tabular}

Table 2: Required procedures/diagnostic examinations interpreted

\begin{tabular}{|c|c|c|}
\hline Procedures/Studies & $\begin{array}{l}\text { No. of Studies } \\
\text { (Minimum) }\end{array}$ & Specifics \\
\hline Total diagnostic examinations interpreted & 3000 & Of which at least 1500 should be MR imaging \\
\hline Vascular imaging interpretation & 250 & $\begin{array}{l}\text { Including CTA, CTV, MRA, MRV, Doppler sonography, and } \\
\text { catheter-based angiography }\end{array}$ \\
\hline $\begin{array}{l}\text { Image-guided invasive procedures } \\
\text { performed }^{\text {a }}\end{array}$ & 100 & $\begin{array}{l}\text { Which may include LP, myelography, advanced spine procedures, } \\
\text { catheter-based angiography, and head and neck biopsies }\end{array}$ \\
\hline
\end{tabular}

Note:-LP indicates lumbar puncture.

${ }^{a}$ Must demonstrate competence in spinal access.

required to interpret $1500 \mathrm{CT}$ examinations and $1500 \mathrm{MR}$ imaging examinations. ${ }^{1}$ While the total number of examinations interpreted has not changed since the prior requirements, the new phrasing allows fellows the opportunity to interpret more advanced MR imaging examinations than previously required. This change allows fellows to concentrate more on complex MRIs than on CTs, to account for CT experience that was likely already gained in residency.

Catheter-Based Angiography and Imaging-Guided Procedures in the New Requirements. Notable changes were made to the catheter-based angiography requirement in 2 sections: Patient Care and Procedural Skills and within the Curriculum section. Fellows are required to interpret a total of 250 vascular studies, which may include a combination of CTA, CTV, MRA, MRV, Doppler sonography, and catheter-based angiography ([IV.B.1. b].[2].[a].[ii]). ${ }^{2}$ Previously, this requirement was met by CTA and MRA alone. Incorporating catheter-based angiography into the interpretive vascular curriculum emphasizes the importance of vascular imaging interpretation rather than the skills needed to perform catheter-based angiography. In addition, within the Curriculum section, it is emphasized that fellows must interpret both noninvasive and invasive neuroangiography. The required rotation length was also decreased from a 6-week minimum to a 4 -week rotation or equivalent (IV.C.7.a). ${ }^{2}$ Fellows are encouraged to participate in catheter-based angiography and to understand the pre- and postprocedural care of these patients.

The procedural requirements were also modified in the updated requirements. While the total number of procedures required has not changed and remains 100 procedures, there is now greater flexibility given to programs to fill this requirement, which may include a combination of DSA, lumbar puncture, myelography, advanced spine procedures, and head and neck biopsies ([IV.B.1.b].[2].[a].[iii]). ${ }^{2}$ Spinal access is the one procedure
Table 3: Curriculum summary

\begin{tabular}{lc}
\hline $\begin{array}{c}\text { Curriculum: Specialty Area of } \\
\text { Concentration }\end{array}$ & $\begin{array}{c}\text { Time/Equivalent Experience } \\
\text { (Minimum) }\end{array}$ \\
\hline Vascular & 4 Weeks or equivalent longitu- \\
dinal experience & Weeks or equivalent longitu- \\
Spine & dinal experience \\
Head and neck & 4 Weeks or equivalent longitu- \\
dinal experience
\end{tabular}

Table 4: Eligibility for US/Canadian candidates

\begin{tabular}{l} 
Eligibility \\
\hline ACGME-accredited residency \\
AOA-approved residency program \\
ACGME International (ACGME-I) Advanced Specialty Accreditation \\
Royal College of Physicians and Surgeons of Canada \\
College of Family Physicians of Canada-accredited residency pro- \\
gram located in Canada
\end{tabular}

Note:-AOA indicates American Osteopathic Association.

Table 5: Alternate pathway for fellowship eligibility ${ }^{a}$ Candidates Must Meet the Following:

Complete a residency in the core specialty outside the US/Canada Demonstrate exceptional clinical excellence compared with peers Demonstrate excellence in research, scholarship, or leadership Verification of ECFMG status

Evaluation of performance by the CCC within 12 weeks of matriculation

Note:-ECFMG indicates Educational Commission for Foreign Medical Graduates; CCC, Clinical Competency Committee.

${ }^{a}$ Fellowship may not lead to certification from American Board of Medical Specialties or AOA certifying boards.

in which fellows are required to demonstrate competence, but the requirements do not specify the number of procedures needed to establish competence ([IV.B.1.b].[2].[b]). ${ }^{2}$ This number will be 


\section{Duty Hours}

80 Hours per week

8 Hours off between clinical work and education periods

Minimum of 1 day in 7 free of clinical work and required education

Cannot exceed 24 hours of continued scheduled clinical service

Must have 14 hours free of clinical work and education following 24 hours of in-house call

Night float: fellows must not be scheduled for shifts greater than every third night

\section{Comments}

Averaged for 4 weeks

Includes all in-house clinical and educational activities Includes moonlighting

Includes at-home call

Clinical work done from home

Averaged for 4 weeks

At-home call cannot be assigned on these free days

Applies to moonlighting

Averaged for 4 weeks variable depending on the previous experience of the fellow gained in residency training. A summary of procedure requirements is listed in Table 2.

The specific requirement regarding the performance of 50 catheter-based angiographies from the prior version was removed from the updated document. The new requirements reflect the current sentiment among many programs around the country that diagnostic neuroradiology fellows are not performing diagnostic angiographies after fellowship. Many program directors and fellows felt that this requirement did not reflect current practice expectations. The new phrasing regarding the procedure requirement emphasizes the importance of patient evaluation and the consent process rather than learning any one specific type of procedure. This flexibility allows individual fellowship programs to distinguish themselves as centers of excellence regarding learning specific types of neuroradiology-related procedures.

While the field of neuroangiography has changed during the past 10 years, with greater involvement from neurosurgery, neurology, vascular surgery, and interventional radiology, there are a number of centers around the country that have neuroradiology-trained Neuroendovascular specialists and would like their fellows to be eligible to apply for a dedicated Neuroendovascular Fellowship. The updated requirements will allow those programs the ability to still achieve this goal.

A point that must be emphasized is that the removal of the required number of catheter-based angiographies performed does not indicate any intent to minimize the value of performing catheter-based angiography as a learning endeavor. Many still believe that being part of the angiography team and performing these procedures strengthens the knowledge of the procedure, the indications, risks and benefits, as well as interpretation of both angiography studies and noninvasive angiography. Thus, programs that provide the opportunity to perform and immerse the fellow in the training are encouraged to continue. The changes allow one to provide this experience without the concern for accreditation issues due to the lower volume of cases.
Curriculum. No major changes were made to the length of time that fellows should spend on pediatric, head and neck, and spine rotations, each specifying a 4-week or equivalent longitudinal experience. There was a change to the vascular requirement, which changed from a 6- to 4-week block to align with the other specialty areas (Table 3). While no specific rotation length was allocated to advanced imaging, fellows must document their exposure to MR spectroscopy and fMRI (IV.C.9.). ${ }^{2}$

Fellow Eligibility. As in the past, individuals interested in applying for an ACGME-accredited Neuroradiology Fellowship must have completed an approved residency training program in the United States or Canada as outlined in Table 4. An alternate pathway for fellowship matriculation is possible, which is outlined in Table 5.

Duty Hours. Duty hours were incorporated within the previous requirements without significant changes. Fellows are responsible for documenting clinical and educational work hours and maintaining a maximum of 80 hours worked per week, when averaged for 4 weeks. Additional specifications related to time off between shifts, moonlighting, in-house call, and home call are listed in Table 6.

\section{Summary}

The ACGME Neuroradiology Fellowship Requirements have been updated to reflect current trends in neuroradiology practice. The new requirements allow fellows to fulfill the foundational expectations for the Neuroradiology Fellowship and allow programs to maintain some flexibility to focus on teaching specialty areas of clinical excellence.

\section{REFERENCES}

1. The ACGME Program Requirements for Graduate Medical Education in Neuroradiology Revised. July 2007. Accessed January 24, 2017

2. The ACGME Program Requirements for Graduate Medical Education in Neuroradiology Revised. July 2019. https://www.acgme.org/Portals/0/ PFAssets/ProgramRequirements/423_Neuroradiology_2019.pdf?ver= 2019-03-20-145727-847. Accessed December 1, 2019 